\title{
Efeitos interativos dos controles gerenciais, das avaliações cognitivas e reações emocionais no comprometimento afetivo
}

\author{
João Teles \\ https://orcid.org/0000-0003-1140-0037
}

Alcindo Cipriano Argolo Mendes

https://orcid.org/0000-0002-1999-7117

Rogério João Lunkes

https://orcid.org/0000-0003-4232-5746

\section{Resumo}

Objetivo: O objetivo do estudo foi analisar os efeitos dos controles gerenciais (CG) no comprometimento afetivo por meio das avaliações cognitivas e reações emocionais. Os controles gerenciais são representados neste estudo por 4 tipos de controle: resultado, ação, pessoal e cultural.

Método: A pesquisa foi realizada por meio de um quase-experimento, com 252 estudantes de graduação da área de gestão e conduzida por quatro cenários simulados, que representaram a adoção dos controles gerenciais. A abordagem foi quantitativa e utilizou-se para análise dos dados a modelagem de equações estruturais, com estimação dos Mínimos Quadrados Parciais (PLS-SEM).

Resultados: O estudo fornece evidências de que cada tipo de controle gerencial é percebido pelos empregados de forma distinta, sendo os controles culturais e de pessoal percebidos de forma mais positiva do que os controles de resultado e de ação. Além disso, quando os indivíduos avaliaram e sentiram os controles de forma positiva, o impacto sobre o comprometimento afetivo foi significativamente maior. Por outro lado, quando avaliaram e sentiram os controles de forma ameaçadora, estes reduziram de forma significativa o comprometimento afetivo.

Contribuição: $\mathrm{O}$ estudo contribui para a literatura ao mostrar que os indivíduos reagem de forma distinta à adoção de controles de resultado, ação, pessoal e cultural. Traz à tona a discussão de que embora os controles gerenciais sejam importantes para influenciar comportamento, é preciso avançar no entendimento sobre o efeito de cada tipo de controle

Palavras-chave: Controles gerenciais; Avaliação cognitiva; Reações emocionais; Comprometimento afetivo. 


\section{Introdução}

Os controles gerenciais são importantes para influenciar o comportamento dos empregados (Cugueró-Escofet \& Rosanas, 2013; Goebel \& Weißenberger, 2017). Estudos ao longo das últimas décadas vêm mostrando que os CGs são capazes de alinhar os objetivos individuais aos organizacionais (Otley, 1999; Merchant \& Van der Stede, 2007; Chenhall \& Moers, 2015). Assim, as organizações precisam direcionar o comportamento dos empregados, com a finalidade de obter o seu comprometimento (Goebel \& Weißenberger, 2017) e com isto atingir seus objetivos organizacionais.

Apesar da densa literatura, pouco ainda se sabe sobre efeitos psicológicos que os diversos tipos de controles gerenciais podem provocar nos funcionários. Tradicionalmente, os CGs são apontados como influenciadores do comportamento. No entanto, os CGs podem ser classificados por tipos diferentes e, além disso, cada empregado pode reagir de uma forma a esses controles.

Por um lado, essas reações podem ser positivas, como satisfação e engajamento no trabalho (Kenis, 1979; Basnet, 2018), melhora da cooperação e do trabalho em equipe (Karia \& Assari, 2006; Christ, Sedatole, Towry \& Thomas, 2008). Esses efeitos positivos impactam a confiança percebida pelo empregado (Walton, 1985; Christ et al., 2008), e o comprometimento afetivo (Goebel \& Weißenberger, 2017), o que contribui para o aumento do desempenho no trabalho (Christ, Summers \& Wood, 2012; Christ, Emett, Tayler \& Wood, 2016). No entanto, a adoção dos controles gerenciais também pode impactar negativamente os empregados, na medida em que são percebidos como ameaça e restringem a autonomia no trabalho (Christ et al., 2008), o que gera respostas emocionais negativas, como frustração, estresse e tensão (Basch \& Fisher, 1998). Desse modo, é provável que reações negativas dos empregados possam interferir no desempenho organizacional.

Ainda são raros os estudos gerenciais que buscam entendimento dos efeitos emocionais e cognitivos dos empregados a partir da adoção de controles gerenciais. Goebel e Weißenberger (2017) indicam que fatores psicológicos podem afetar indiretamente a relação entre os controles gerenciais e o desempenho dos empregados. Assim, estudos têm encontrado dificuldades para explicar como os empregados se comportam quando interagem com os diversos tipos de controles gerenciais, como controles de resultado, ação, pessoal e cultural (Merchant \& Van der Stede, 2007). Neste estudo pretende-se preencher uma lacuna sobre os diferentes efeitos dos controles de resultado, ação, pessoal e cultural sobre o comprometimento afetivo dos empregados. Mais especificamente, conhecer o efeito da adoção de cada tipo de controle na avaliação cognitiva e a reação emocional e, consequentemente, no comprometimento afetivo.

Para isso, este estudo analisará o comportamento dos empregados a partir da perspectiva da literatura de emoções, abordadas na Teoria dos Eventos Afetivos (TEA). Weiss e Cropanzano (1996) propõem que eventos no trabalho provocam reações emocionais individuais, influenciando as atitudes posteriores. Para Weiss e Cropranzano (1996, p. 12), "as consequências da experiência afetiva são atitudinais e comportamentais". Nessa linha teórica, afetos positivos no trabalho são relacionados à influências sobre a espontaneidade organizacional (George \& Brief, 1992), cidadania organizacional (Ilies, Scott, \& Judge, 2006; Spence, Ferris, Brown \& Heller, 2011), e menores taxas de absenteísmo (George, 1989), enquanto afetos negativos estão associados a comportamentos contraproducentes, como agressão e sabotagem (Ashkanasy \& Humphrey, 2011).

Portanto, as avaliações realizadas pelos indivíduos sobre os tipos de controles gerenciais são particularmente importantes, pois definem a maneira com que os empregados vão responder a esses controles, e como vão se comprometer com os objetivos organizacionais. Na perspectiva adotada por este estudo, o comportamento de cada funcionário é resultante de um processo interno (intra corpus), composto por aspectos cognitivos, emocionais e atitudinais. Consequentemente, entende-se que os tipos de controles gerenciais impactam emocionalmente os empregados a partir de uma interpretação individual das situações que ocorrem na organização. Sendo assim, deve-se considerar que a adoção de controles de resultados, ação, pessoal e cultural será avaliada de forma diferente pelos empregados, provocando reações emocionais e atitudes distintas. Assim, o objetivo do estudo é analisar os efeitos dos tipos de controles gerenciais no comprometimento afetivo por meio das avaliações cognitivas e reações emocionais. 
A pesquisa foi realizada por meio de um quase-experimento, no qual estudantes foram submetidos a um cenário de adoção de cada tipo de controle. Em seguida, foram captadas a avaliação cognitiva e a reação emocional que definiram o seu nível de comprometimento afetivo com a organização. Nesse sentido, a pesquisa contribui com a pesquisa comportamental em contabilidade gerencial, trazendo relações entre variáveis gerenciais e aspectos emocionais. Mais especificamente, contribui ao mostrar que os controles cultural e de pessoal são percebidos de forma mais positiva (desafio), do que os controles de resultado e de ação. Com isso, o estudo mostra evidências de que os tipos de controles são percebidos e afetam os empregados de forma distinta.

Assim, este estudo avança no conhecimento sobre as emoções e decisões tomadas no ambiente de trabalho (Birnberg \& Ganguly, 2012), ao analisar o efeito dos controles gerenciais nas reações dos empregados. Esse conhecimento pode contribuir para melhorar a eficiência na adoção dos sistemas de controles gerenciais e, consequentemente, direcionar o comprometimento para atingir os objetivos organizacionais. Também contribui ao mostrar que os gestores devem ter um cuidado especial na adoção de certos tipos de controle como de ação e resultados, visando evitar efeitos colaterais para a organização.

\section{Revisão de literatura e desenvolvimento de hipóteses}

\subsection{Teoria dos Eventos Afetivos (TEA)}

O estudo sobre afeto no ambiente de trabalho surgiu nos EUA na década de 1930 com uma diversidade de ideias e métodos, buscando entender os sentimentos dos trabalhadores (Fisher \& Hanna, 1931; Kornhauser \& Sharp, 1932; Hersey, 1932; Hoppock, 1935; Roethlisberger \& Dickson, 1939). A diversidade nos anos 1930 foi substituída por uma linha de pesquisa predominante sobre satisfação no trabalho, focada em observações empíricas, na busca pelo entendimento sobre os antecedentes dessa satisfação (Weiss \& Cropanzano, 1996). Nesse período, foram desenvolvidas medidas para as atitudes no trabalho, fato que proporcionou ganho na confiabilidade e validade das pesquisas (Brief \& Weiss, 2002).

A Teoria dos Eventos Afetivos - TEA (Affective Events Theory), proposta por Weiss e Cropanzano (1996), destaca o papel das emoções no trabalho ao considerar que determinados eventos causam reações emocionais no trabalho, o que influencia as atitudes e comportamentos dos indivíduos. Esses eventos são chamados de 'eventos afetivos'. Como apontado na TEA, o afeto é uma variável de mediação entre fatores organizacionais e fatores afetivos (Ashkanasy, Härtel \& Daus, 2002).

Os eventos afetivos são avaliados por um processo cognitivo, que envolve a relevância do evento para o bem-estar pessoal e sua importância. A avaliação inicial é seguida por uma avaliação mais específica que enfoca dimensões como o potencial de enfrentamento e as consequências do evento. Essas avaliações produzem a experiência de emoções como alegria (positiva) ou raiva (negativa). Sobre a maneira que o afeto influencia as atitudes e o comportamento, Weiss e Cropanzano (1996) argumentam que as atitudes compreendem tanto um elemento afetivo quanto um elemento de julgamento cognitivo.

A avaliação cognitiva é a percepção sobre um evento em relação à relevância para o bem-estar pessoal, determinando a intensidade e a qualidade dos sentimentos, as tendências de ação, respostas fisiológicas e comportamento (Roseman, Spindel \& Jose, 1990; Lazarus, 1991a; Clore \& Ortony, 2000; Frijda, 2004). As avaliações dos funcionários sobre mudanças organizacionais são cruciais, pois definem a forma como os empregados atendem às mudanças (Fugate, Harrison \& Kinicki, 2011). 
A avaliação cognitiva de desafio (facilitação dos objetivos) leva a estados emocionais agradáveis (Weiss \& Cropanzano, 1996), enquanto a avaliação cognitiva de ameaça é um indicador de perda potencial no futuro e de confiança nos gestores, portanto, captura as preocupações voltadas para o futuro dos empregados. Essa orientação cognitiva permite que os gestores sejam proativos no tratamento das preocupações dos empregados e na mitigação de reações indesejáveis como a saída de empregados valorizados (Biggane, 2016).

As emoções podem ser entendidas como estados internos da pessoa, envolvendo interações entre o sujeito e um objeto, tais como sentimentos, estados de bem-estar ou ativação de determinado padrão motor (Frijda, 2004). As reações emocionais geralmente iniciam com uma avaliação sobre um evento (Plutchik, 1994). Essas reações podem ser entendidas a partir de duas dimensões independentes que representam as suas valências: afeto positivo e afeto negativo. $\mathrm{O}$ afeto positivo reflete o grau em que alguém se sente entusiasmado, ativo e alerta, enquanto o afeto negativo diz respeito à extensão em que uma pessoa sente raiva, desprezo, repulsa, medo ou nervosismo (Watson, Clark \& Tellegen, 1984).

O modelo de pesquisa proposto é derivado da TEA (Weiss \& Cropanzano, 1996), assumindo as "reações emocionais" como uma variável importante na compreensão de como os eventos no local de trabalho afetam os resultados relacionados ao trabalho (comprometimento afetivo). Como o foco da pesquisa é a adoção de controles gerenciais, representando eventos específicos no local de trabalho, as reações emocionais foram operacionalizadas como estados emocionais (afeto positivo e afeto negativo). Além disso, as avaliações cognitivas também estão incluídas nessa operacionalização, pois como Weiss e Cropanzano (1996, p. 37) destacam: "a experiência do afeto está intrinsecamente ligada à avaliação desse evento". Sendo assim, adota-se a premissa que as pessoas estão constantemente avaliando as interações com o ambiente no que diz respeito às implicações para o seu bem-estar, caracterizando-se como um elemento-chave para o entendimento dos efeitos individuais dos CGs, atuando como um filtro entre o estímulo recebido e as respostas geradas a partir disso (Lazarus, 1991b).

\subsection{Controles gerenciais e avaliação cognitiva}

O controle gerencial compreende todas as formas e sistemas que os gestores usam para assegurar que os comportamentos e decisões de seus empregados estejam consistentes com os objetivos e estratégias da organização. Merchant e Van der Stede (2007) propõem quatro tipos de CG que enfatizam as dimensões social e comportamental dos controles, que serão detalhados por constituírem a base teórica adotada para operacionalização deste estudo. Adotando essa perspectiva teórica, são apresentados os tipos de controles: (i) controles de resultados; (ii) controles de ação; (iii) controles de pessoal; e (iv) controles culturais.

Os controles de resultados focam na mudança do comportamento dos empregados com ênfase na sua motivação, por meio de sistemas de incentivos e punições (Herath, 2007). A ênfase dos controles de resultados está na eficiência, conformidade e realização dos objetivos, atuando sobre os aspectos comportamentais das operações (Hopwood, 1972). Na adoção de controles de resultados, espera-se do subordinado um empoderamento profissional sobre as consequências das ações tomadas, criando meritocracia e recompensando-o por bons resultados. Isso porque esses controles são geralmente utilizados para influenciar o comportamento dos empregados em situações em que os resultados podem ser controlados (Merchant \& Van der Stede, 2007). 
Controles de ação visam motivar o envolvimento no trabalho dos empregados (Long, 2018) e podem ser caracterizados como controles comportamentais diretos por atuarem inteiramente sobre o indivíduo, na supervisão, orientação ou restrição de suas ações. Têm a função de assegurar que todos saibam quais as ações desejadas ou não para o benefício da organização. As organizações adotam controles de ação e monitoram a implementação das normas para garantir que seus empregados usem métodos apropriados para a conclusão das tarefas (Van Maanen \& Schein, 1977).

Controles de pessoal têm por objetivo motivar relações interpessoais positivas (Long, 2018) e são adotados para desenvolver habilidades e competências dos empregados, bem como, atividades de socialização para promover congruências e sua adequação à organização (Van Maanen \& Schein, 1977). Controles culturais podem ser representados pelo conjunto de crenças e cultura organizacional e podem ser expressos na missão, visão e valores da organização, o que permite o monitoramento mútuo dos empregados (Merchant \& Van der Stede, 2007). Os códigos de ética são exemplos da formalização desses controles.

Controles de pessoal e culturais são capazes de estimular a autonomia individual e criam um ambiente de trabalho baseado na compreensão sobre a importância dos objetivos organizacionais. Esse entendimento compartilhado constitui um fator importante que influencia o comprometimento dos empregados, ao reforçar um senso de propósito organizacional (Hernandez, 2008). Portanto, espera-se que controles de pessoal e culturais provoquem um "alto comprometimento como resultado de valores internacionalizados" (Ouchi, 1979, p. 841).

A adoção de um determinado tipo de controle gerencial (de resultado, ação, pessoal e cultural) em uma organização, pode ser entendida como um evento que proporciona o processo de criação de significados nos indivíduos, os levando a questões sobre a relevância do próprio evento (Liu \& Perrewé, 2005). Assim, a adoção de CG pode influenciar o comportamento de forma positiva, alinhando os interesses individuais aos interesses organizacionais, ou de forma negativa, confrontando com os objetivos pessoais dos empregados, provocando respostas emocionais que favoreçam comportamentos indesejáveis para a organização.

A adoção de CG pode despertar um sentimento de incerteza nos empregados em relação ao futuro, o que por sua vez leva ao medo e à ansiedade (Sutton \& Kahn, 1987). Quando o desafio domina a avaliação cognitiva, os empregados perceberão um nível mais alto de congruência dos objetivos, acreditando que a mudança tem mais chances de ser bem-sucedida e, assim, influenciando sua avaliação geral sobre a mudança planejada (Liu \& Perrewé, 2002). Por outro lado, os empregados podem perceber a adoção dos CGs de forma positiva, com maior senso de controle percebido (Cobb, Wooten \& Folger, 1995). Nesse caso, a mudança traz esperança aos empregados, tornando-os emocionalmente entusiasmados e, assim, elevando suas expectativas para um sucesso futuro (Dutton, Ashford, O’neill, Hayes \& Wierba 1997; Huy, 2002).

Em eventos como a adoção de CG, os empregados tendem a definir suas atitudes a partir do seu estado emocional, que pode apresentar uma variedade afetos positivos ou negativos provocados pelas avaliações individuais. Assim, espera-se que a adoção dos tipos de CG (resultados, de ação, de pessoal e culturais) afetará de forma diferente as avaliações cognitivas. O indivíduo pode perceber a adoção de determinado tipo de controle de forma positiva como um desafio, bem como de forma negativa como uma ameaça. Mais do que isso, argumenta-se que cada tipo de CG causará níveis diferentes de avaliação cognitiva (desafio ou ameaça) e, dessa forma, as primeiras hipóteses de pesquisa são as seguintes:

H1 (a-b-c-d): A percepção sobre a adoção de CG a) controles de resultados, b) controles de ação, c) controles de pessoal, e d) controles culturais tem uma relação positiva com a avaliação cognitiva de desafio.

H2(a-b-c-d): A percepção sobre a adoção de CG a) controles de resultados, b) controles de ação, c) controles de pessoal, e d) controles culturais tem uma relação negativa com a avaliação cognitiva de ameaça. 


\subsection{Avaliação cognitiva e reações emocionais}

A avaliação cognitiva de um indivíduo sobre um determinado evento é feita com base na relevância do evento para o bem-estar individual e está intrinsecamente ligada ao conjunto de objetivos e valores do indivíduo (Frijda, 1993). Os danos ou benefícios percebidos dependem do comprometimento com os objetivos que residem na pessoa e são frustrados ou facilitados pelo comportamento do ambiente (Lazarus, 1991a). Dessa maneira, a avaliação inicial envolve um julgamento sobre a relevância e congruência do objetivo, na qual o evento toca em alguma questão de desejo pessoal ou preocupação. Ortoni, Clore e Collins (1990) defendem conjuntos de categorias ou famílias de emoções relativamente independentes, baseadas em processos de avaliação comuns como o produto final do processo de avaliação cognitiva.

Além disso, argumentam que a relevância do objetivo é essencial para as reações emocionais aos eventos, como a adoção de CG, e que a intensidade da emoção está diretamente correlacionada com a importância ou a conveniência do objetivo. Significa dizer que as reações emocionais dos empregados dependem diretamente da avaliação cognitiva que fazem na adoção do tipo de CG. Isso porque as pessoas têm uma ampla variedade de objetivos que afetam as reações emocionais (Weiss \& Cropanzano, 1996). Teóricos sobre emoções concordam que estados emocionais específicos existem e são provocadas pela ação de avaliações cognitivas (Plutchik, 1994).

Esses estados emocionais resultam de um processo de avaliação de dois estágios, no qual a avaliação envolve uma percepção acerca se o evento é de desafio ou de ameaça (Frijda, 1986; Lazarus, 1991a). As avaliações desafiadoras levam a reações emocionais positivas, enquanto que as avaliações ameaçadoras levam a reações emocionais negativas. Sendo assim, as avaliações cognitivas de desafio e ameaça correspondem ao tom hedônico (prazer/satisfação) que o indivíduo apresentará (Weiss \& Cropanzano, 1996).

Os achados de Trivellas, Reklitis e Platis (2013) no setor hospitalar fornecem evidências de que a avaliação cognitiva positiva está relacionada a afetos positivos, que pode resultar, por exemplo, na intenção de permanecer no emprego. Sobre as avaliações cognitivas negativas, o estudo de Fugate, Harrison e Kinicki (2011) confirmou empiricamente a relação entre a avaliação cognitiva de ameaça e afeto negativo no que diz respeito à percepção sobre a adoção de CG. Tendo em mente que avaliações cognitivas de desafio sobre os CGs (resultados, de ação, de pessoal e culturais) geram afeto positivo, e que avaliações cognitivas de ameaça geram afeto negativo, propõem-se as seguintes hipóteses de pesquisa:

H3(a-b-c-d): Se a adoção de CG a) controles de resultados, b) controles de ação, c) controles de pessoal, e d) controles culturais for percebida como desafiadora, a avaliação cognitiva de desafio aumenta o afeto positivo.

H4(a-b-c-d): Se a adoção de CG a) controles de resultados, b) controles de ação, c) controles de pessoal, e d) controles culturais forem percebidos de forma ameaçadora, a avaliação cognitiva de ameaça aumenta o afeto negativo.

\subsection{Reações emocionais e comprometimento afetivo}

Uma emoção faz com que alguém esteja pronto para responder a estímulos particulares com ações específicas. Essa concepção permite inferir que uma emoção aumenta a prontidão para executar várias ações diferentes, dependendo das condições do estímulo (Roseman, Wiest \& Swartz, 1994). Sendo assim, as reações emocionais de ameaça ou desafio podem afetar o comprometimento afetivo. Comprometimento afetivo é o grau em que o colaborador se sente emocionalmente ligado, identificado e envolvido na organização (Meyer \& Allen, 1997). 
Russell e Carroll (1999) mostraram que afetos positivos e negativos são estados independentes, em vez de dois polos opostos da mesma dimensão. Ou seja, o afeto positivo pode ser acompanhado por níveis altos ou baixos de afeto negativo, da mesma forma que o afeto negativo. Essa independência sugere que é possível os efeitos positivos compensarem os efeitos nocivos presentes em baixos indicadores de satisfação no trabalho, com isso, ampliarem e construírem repertórios de ação do pensamento dos indivíduos (Fredrickson, 1998).

Embora Lazarus (1991b) aponte que as reações emocionais positivas não possuem tendências de ação individual claras, argumenta-se que tais reações influenciam as ações individuais na medida em que constroem a força humana (Fredrickson, 1998). A alegria, por exemplo, promove a criatividade individual, amplia a mentalidade dos indivíduos e fortalece seus laços sociais. Empregados alegres e orgulhosos são capazes de enfrentar os problemas com mais resiliência (Fredrickson, 1998). Uma situação nova pode incentivar o interesse e a exploração, e assim, aumentar a probabilidade de obter novos conhecimentos e competências. Assim, reações emocionais positivas têm influência positiva na permanência de empregados e no comprometimento com a organização (Ashkanasy \& Daus, 2002).

Uma proposição central da Teoria dos Eventos Afetivos é que as atitudes dos empregados são influenciadas pelos eventos no trabalho. Mais especificamente, a TEA posiciona reações afetivas como um mediador da relação entre eventos e atitudes no trabalho. $\mathrm{O}$ argumento da manutenção do bem-estar sustenta que as emoções positivas promovem os desejos de manter e prolongar o estado atual (Weiss \& Cropanzano, 1996). Atitudes e comportamentos dos empregados são reflexos de suas percepções e expectativas pessoais, retribuindo o tratamento que recebem da organização.

A adoção de CG que gera as avaliações cognitivas de desafio e afetos positivos promovem o comprometimento afetivo. Evidências empíricas relatam que a adoção de comportamentos éticos por parte dos líderes aumenta o comprometimento afetivo dos seus empregados, no que se refere ao orgulho que sentem pela organização, na preocupação com o seu futuro e na partilha dos seus valores (Matela, 2016). Neubert, Carlson, Kacmar, Roberts e Chonko (2009) defendem que os comportamentos de liderança ética devem promover uma atmosfera moral na organização, estimulando a satisfação profissional e o comprometimento afetivo. Os resultados de Goebel e Weißenberger (2017) reforçam esse entendimento, confirmando as hipóteses que controles de pessoal e culturais influenciam positivamente o comprometimento. Tendo em mente essas evidências, conjuntura-se que o afeto positivo leva a um aumento do comprometimento afetivo, e que afeto negativo leva a sua diminuição. Assim, espera-se nas hipóteses seguintes que:

H5(a-b-c-d): Afetos positivos decorrentes da adoção de CG a) controles de resultados, b) controles de ação, c) controles de pessoal, e d) controles culturais provocam aumento no comprometimento afetivo.

H6(a-b-c-d): Afetos negativos decorrentes da adoção de CG a) controles de resultados, b) controles de ação, c) controles de pessoal, e d) controles culturais provocam diminuição no comprometimento afetivo.

O modelo teórico da pesquisa está representado na Figura 1, no qual cada tipo de controle provocará uma avaliação cognitiva, representadas pelas hipóteses H1 e H2. Essa avaliação cognitiva, de acordo com a Teoria dos Eventos Afetivos pode ser desafiadora e/ou ameaçadora em alguma medida. Conforme a avaliação cognitiva do empregado, ele terá reações emocionais que podem ser mais positivas (afeto positivo) ou mais negativas (afeto negativo), expressas nas hipóteses $\mathrm{H} 3$ e H4. Essas reações determinarão a influência no comprometimento afetivo que o empregado terá com as tarefas definidas nos controles gerenciais ( $\mathrm{H} 5$ e $\mathrm{H} 6)$. 


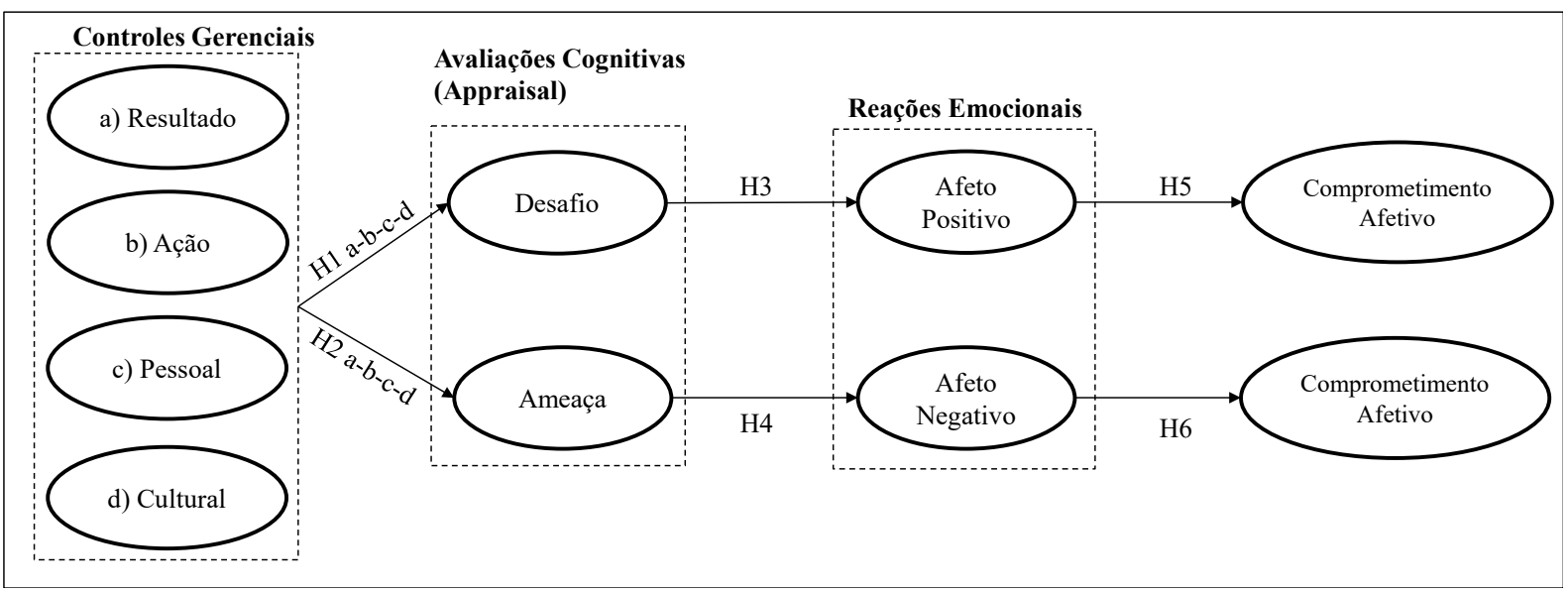

Figura 1. Modelo teórico da pesquisa

\section{Procedimentos metodológicos}

\subsection{Desenho experimental}

Para o desenho do estudo, foi definida a aplicação de testes experimentais que permitissem analisar efeitos individuais por meio de eventos simulados pelos pesquisadores (pitches). Esses pitches objetivaram manipular a adoção de controles de resultado, ação, pessoal e cultural, de maneira que o participante pudesse identificar os efeitos do controle gerencial no comprometimento afetivo.

Não houve aleatorização dos participantes às condições experimentais por se tratar de um estudo "within subjects" sem grupo de controle. De acordo com Charness, Gneezy e Khun (2012), estudos experimentais within subjects não dependem de atribuição aleatória para melhorar a sua validade interna. Além disso, estão mais alinhados com posicionamentos teóricos onde um indivíduo responde a um estímulo do experimentador. Nesse sentido, classifica-se o presente estudo como quase-experimento (Shadish, Cook \& Campbell, 2002)

A elaboração dos pitches foi com base nos trabalhos de Kleine e Weißenberger (2014), Goebel e Weißenberger (2017) e Long (2018), conforme Figura 2.

\begin{tabular}{|c|c|c|c|}
\hline Construtos & Dimensões & Instrumento de pesquisa & Referências \\
\hline \multirow{4}{*}{$\begin{array}{l}\text { Controle Gerencial } \\
\text { (CG) }\end{array}$} & Controle de Resultado (CR) & Cenário 1 & \multirow{4}{*}{$\begin{array}{c}\text { Kleine e Weißenberger } \\
\text { (2014); Goebel e } \\
\text { Weißenberger (2017) }\end{array}$} \\
\hline & Controle de Ação (CA) & Cenário 2 & \\
\hline & Controle de Pessoal (CP) & Cenário 3 & \\
\hline & Controle Cultural (CC) & Cenário 4 & \\
\hline \multirow{2}{*}{ Avaliação Cognitiva } & Ameaça (AME) & \multirow{2}{*}{ Escala de Avaliação Cognitiva } & \multirow{2}{*}{$\begin{array}{c}\text { Gomes, Faria e } \\
\text { Gonçalves (2013) }\end{array}$} \\
\hline & Desafio (DES) & & \\
\hline \multirow{2}{*}{ Reações Emocionais } & Afeto Positivo (AP) & \multirow{2}{*}{ PANAS-VRP } & \multirow{2}{*}{$\begin{array}{l}\text { Galinha, Pereira e } \\
\text { Esteves (2014) }\end{array}$} \\
\hline & Afeto Negativo (AN) & & \\
\hline $\begin{array}{c}\text { Comprometimento } \\
\text { Afetivo }\end{array}$ & Comprometimento Afetivo (CAF) & $\begin{array}{l}\text { Escala de Comprometimento } \\
\text { Afetivo para a mudança }\end{array}$ & $\begin{array}{l}\text { Herscovitch e Meyer } \\
\text { (2002) }\end{array}$ \\
\hline
\end{tabular}

Figura 2. Constructos e operacionalização do objetivo de pesquisa 
Os pitches foram vídeos curtos com comunicações da diretoria via e-mail sobre a adoção de controles gerenciais: de resultado, de ação, de pessoal e cultural. Foram elaborados quatro vídeos, cada um representando um tipo de controle. Após cada vídeo, os participantes responderam um questionário com quatro blocos, que identificou a percepção sobre a adoção do controle, as avaliações cognitivas de desafio e ameaça, as reações emocionais positivas e negativas e o comprometimento afetivo. A Figura 2 apresenta os constructos utilizados na pesquisa e sua operacionalização.

Para a apresentação dos controles (de resultado, de ação, de pessoal e cultural) do CG foram elaborados 4 cenários. O cenário 1 contempla o controle de resultado, e envolve um comunicado sobre a adoção de metas de desempenho aos funcionários, com bônus para aqueles que atingirem os resultados individuais, além de promoção para aqueles com os melhores resultados e a necessidade de justificativa para aqueles funcionários que não atingirem as metas. O cenário 2 (controle de ação) envolve um comunicado para os funcionários sobre acesso aos computadores da empresa, com o uso de senha pessoal, acesso limitado à internet, de acordo com as necessidades de cada gerência. Os gerentes terão acesso ao histórico das atividades realizadas nos computadores e controlarão o uso do WhatsApp durante o expediente. O cenário 3 sobre os controles de pessoal, envolve um comunicado sobre a realização de treinamentos a cada dois sábados, com o objetivo de promover interações e ampliar a gama de capacidades dos funcionários. Já o cenário 4 (controles culturais) abarca a comunicação do código de ética baseado nos pilares de segurança, pessoas, excelência, foco nos resultados e sustentabilidade. Os funcionários devem agir de acordo com as diretrizes deste código de ética. Os itens, escalas e vídeos utilizados estão disponíveis em: https://drive.google.com/drive/folders/1zBkzxlrHQinAbunmJD4624Njual3DtqD.

A partir da comunicação de cada vídeo foi aplicado o questionário com os seguintes blocos:

- Bloco 1 (CG): O controle gerencial foi divido em 4 tipos (de resultado, de ação, de pessoal e cultural). Cada tipo de controle foi formado por 5 questões baseados no estudo de Goebel e Weißenberger (2017). Para medir cada questão do questionário, foi utilizada a escala de Likert de 7 pontos (1: discordo totalmente e 7: concordo totalmente).

- Bloco 2 (Avaliação cognitiva): A avaliação cognitiva foi dividida em ameaça e desafio. Neste item, em relação à situação apresentada (controle de resultado, ação, pessoal e cultural), o respondente indicava, considerando seu ponto de vista pessoal (perturbadora, ameaçadora, negativa, estimulante, excitante e desafiadora) em uma escala Likert de 7 pontos (1: não e 7: muito), como percebe a situação (Gomes, Faria \& Gonçalves, 2013).

- Bloco 3 (Reações emocionais): As reações emocionais foram classificadas em afeto positivo e afeto negativo. Este constructo envolve 10 itens, em que 1 significa nada/muito ligeiramente e 5 extremamente, visando medir o sentimento em relação ao controle apresentado (interessado, nervoso, entusiasmado, amedrontado, inspirado, ativo, assustado, culpado, determinado e atormentado). As medidas da PANAS-VRP são amplamente utilizadas na literatura (Galinha et al., 2014).

- Bloco 4 (Comprometimento afetivo): O comprometimento afetivo pode ser concebido como um estado psicológico, que caracteriza a ligação dos indivíduos à organização (Meyer \& Allen, 1997). Para medir essa variável, foi utilizada a escala de Likert de 5 pontos (1: nada e 5: extremamente) de comprometimento afetivo para a mudança (Herscovitch \& Meyer, 2002).

- Bloco 5 (Variáveis de controle): O último bloco solicitou dados sobre o respondente como: sexo, idade, curso, tempo no curso, turno, estado civil e tempo de experiência profissional. 


\subsection{Protocolo de validade experimental}

Inicialmente, foram feitos pré-testes com seis professores para ajustes do instrumento utilizado no quase-experimento, sendo quatro da área de Contabilidade Gerencial, um da Psicologia Organizacional e outro da Tecnologia da Informação. Também foram realizados pré-testes com três alunos e quatro profissionais de mercado. Em seguida, foram feitos ajustes nos vídeos dos cenários e no texto do questionário para melhor compreensão.

Para confirmação do entendimento por parte dos respondentes sobre os controles gerenciais, colocaram-se, ao final, questões adicionais quanto à clareza e compreensão das perguntas respondidas. Para validação do instrumento de pesquisa utilizado no estudo, foi utilizado o protocolo sugerido por Kim (2009), conforme Figura 3.

\begin{tabular}{|c|c|c|c|}
\hline Etapa & Protocolo & Objetivos & Técnicas aplicadas \\
\hline 1 & $\begin{array}{l}\text { Validade de } \\
\text { conteúdo }\end{array}$ & Examinar o quão abrangente os itens representam o constructo & $\begin{array}{l}\text { Julgamento de } \\
\text { experts }\end{array}$ \\
\hline \multirow{3}{*}{2} & Pré-teste & $\begin{array}{l}\text { Comunicar aos respondentes o que o instrumento pretende } \\
\text { comunicar, analisando a operacionalização dos elementos } \\
\text { envolvidos, por meio de teste preliminar do instrumento }\end{array}$ & $\begin{array}{l}\text { Abordagem pessoal } \\
\text { (entrevista }+ \\
\text { questionário }\end{array}$ \\
\hline & Teste piloto & $\begin{array}{l}\text { Determinar se o instrumento projetado efetivamente mede o } \\
\text { objetivo da pesquisa, por meio de um teste preliminar em uma } \\
\text { amostra conveniente e semelhante à população-alvo, permite } \\
\text { aos pesquisadores antecipar os resultados do estudo }\end{array}$ & $\begin{array}{l}\text { Teste preliminar } \\
\text { usando amostra por } \\
\text { conveniência }\end{array}$ \\
\hline & $\begin{array}{l}\text { Validade da } \\
\text { manipulação }\end{array}$ & $\begin{array}{l}\text { Averiguar relações causais entre variáveis independentes } \\
\text { e dependentes, demonstrando que o tratamento das } \\
\text { manipulações é relacionado a medidas "diretas" dos constructos } \\
\text { projetados }\end{array}$ & Manipulation checks \\
\hline \multirow[t]{2}{*}{3} & Confiabilidade & $\begin{array}{l}\text { Demonstrar a consistência dos itens medidos e sua correlação } \\
\text { entre as medidas do mesmo constructo. Sem essa etapa, } \\
\text { os dados não podem ser confiáveis, não possibilitando ao } \\
\text { pesquisador afirmar se correlações insignificantes são devidas } \\
\text { à baixa confiabilidade ou a baixas correlações entre os } \\
\text { constructos }\end{array}$ & $\begin{array}{l}\text { Consistência } \\
\text { interna; } \\
\text { Confiabilidade dos } \\
\text { itens }\end{array}$ \\
\hline & $\begin{array}{l}\text { Validade de } \\
\text { constructo }\end{array}$ & $\begin{array}{l}\text { Determinar se os itens operacionalizados medem o conceito } \\
\text { pretendido para análise, por meio da correspondência entre um } \\
\text { constructo observável e uma suposta medida dele }\end{array}$ & $\begin{array}{l}\text { Validade } \\
\text { convergente e } \\
\text { discriminante }\end{array}$ \\
\hline
\end{tabular}

Figura 3. Protocolo de validade experimental

\subsection{Coleta dos dados}

Os dados da pesquisa foram coletados com estudantes dos cursos de Ciências Contábeis e Administração de uma Instituição de Ensino Superior (IES). Escolhe-se o cenário experimental com estudantes de graduação por alguns motivos. Primeiramente, nosso modelo não prevê a mudança na variável dependente decorrente de diferenças no perfil dos participantes. Em geral, estudantes têm características mais homogêneas, o que reduz o erro de estimação do efeito da variável independente sobre a dependente, contribuindo para um maior poder de explicação dos resultados e maior validade estatística (Aguiar, 2017). 
As aplicações ocorreram em salas previamente preparadas com equipamento para reprodução audiovisual, testadas pelo pesquisador e assistente, para perfeito entendimento e compreensão dos vídeos. Anteriormente à apresentação dos cenários, os participantes foram orientados a se colocar na posição de um empregado recém-contratado em uma empresa, representando o contexto da pesquisa. Após questionar se havia alguma dúvida sobre as orientações, foram reforçados alguns pontos ao iniciar a projeção dos vídeos: "Você participará de um estudo experimental sobre os efeitos de sistemas de controle gerencial nos indivíduos. Tente ao máximo se colocar no lugar do empregado na situação apresentada. Não há respostas certas ou erradas. O objetivo é saber a sua percepção e sentimentos sobre a situação apresentada".

Após a apresentação de cada controle gerencial, os participantes responderam ao instrumento desenvolvido para a pesquisa. Após todos finalizarem o primeiro questionário, o pesquisador se colocou à disposição para eventuais questionamentos e dúvidas dos participantes. Logo após dirimir as dúvidas era dado prosseguimento às outras três simulações do estudo. O tempo médio total das simulações, por sessão, foi de 40 minutos e as aplicações ocorreram nos dias 7 a 9 de novembro de 2018. Foram consideradas para análise dos dados, 252 respostas. A Tabela 1 apresenta o perfil dos participantes da pesquisa.

Tabela 1

Perfil dos participantes da pesquisa

\begin{tabular}{lcrlrc}
\hline \multicolumn{1}{c}{ Gênero } & $\mathbf{N}$ & $\mathbf{\%}$ & \multicolumn{1}{c}{ Estado Civil } & $\mathbf{N}$ & \% \\
\hline Feminino & 141 & 56.00 & Solteiro & 216 & 85.70 \\
Masculino & 111 & 44.00 & Casado & 36 & 14.30 \\
Total & 252 & 100.00 & Total & 252 & 100.00 \\
\hline $\begin{array}{l}\text { Tempo no curso } \\
\text { (graduação) }\end{array}$ & $\mathbf{N}$ & $\%$ & Estatística Descritiva & Idade & $\begin{array}{c}\text { Experiência } \\
\text { (em anos) }\end{array}$ \\
\hline $1^{\circ}$ ano & 63 & 25.00 & Mínimo & 17 & 0 \\
$2^{\circ}$ ano & 94 & 37.30 & Máximo & 45 & 28 \\
$3^{\circ}$ ano & 86 & 34.13 & Média & 23,7 & 4,0 \\
$4^{\circ}$ ano & 9 & 3.57 & Mediana & 22,0 & 2,3 \\
Total & 252 & 100.00 & Desvio Padrão & 5,497 & 4,449 \\
\hline
\end{tabular}

Para minimizar possíveis efeitos de fadiga e maturação dos participantes, adotou-se como estratégia de aplicação a randomização dos cenários apresentados para cada grupo, nos quais todos os cenários foram aplicados em todas as ordens possíveis (ex: Exp. 1 - controle de resultado, foi o primeiro a ser apresentado ao grupo 1. Para o grupo 2, foi apresentado por último. Para o grupo 3, foi apresentado como o terceiro cenário e para o grupo 4 foi apresentado como o segundo cenário), conforme evidenciado na Figura 4.

\begin{tabular}{ccl}
\hline Grupo & Participantes & Ordem dos cenários aplicados \\
\hline Grupo 1 & 90 & Cenário 1; Cenário 2; Cenário 3; Cenário 4 \\
\hline Grupo 2 & 62 & Cenário 2; Cenário 3; Cenário 4; Cenário 1 \\
\hline Grupo 3 & 66 & Cenário 3; Cenário 4; Cenário 1; Cenário 2 \\
\hline Grupo 4 & 34 & Cenário 4; Cenário 1; Cenário 2; Cenário 3 \\
\hline
\end{tabular}

Figura 4. Ordem dos cenários aplicados aos grupos de pesquisa

Em seguida, foram feitos testes não paramétricos para verificar se havia diferença entre os quatro grupos, o que possibilitou considerar que a forma de coleta dos dados não influenciou na forma de análise, por se tratar de amostras independentes (Field, 2009). Utilizou-se o teste U de Mann-Whitney, indicado para variáveis categóricas e ordinais, como é o caso desta pesquisa (Fávero, Silva, Belfiore \& Chan, 2009). 
Por se tratar de uma pesquisa com seres humanos, o projeto de pesquisa foi submetido e aprovado por comitê de ética de pesquisa, com orientações que dizem respeito a: (i) sigilo absoluto dos dados; (ii) o estudo não representa risco aos participantes, desejando a opinião do acadêmico em uma situação hipotética; (iii) possibilidade de desistência da pesquisa a qualquer momento da aplicação; e (iv) tempo estimado de participação de trinta e cinco minutos.

\subsection{Análises dos dados}

Para analisar os modelos da pesquisa, empregou-se a análise multivariada exploratória conhecida como Partial Least Squares Structural Equation Modeling (PLS-SEM), que constitui uma técnica de modelagem de equações estruturais baseada em variância (Hair Jr., Hult, Ringle \& Sarstedt, 2016). Entre as vantagens da análise por meio do PLS-SEM, pode-se destacar: (i) é considerada a segunda geração de análise multivariada e tem sido cada vez mais proposta para superar limitações das técnicas mais tradicionais de análise estatística, devido às suas características avançadas (Fornell, 1985); (ii) oferece flexibilidade para testar modelos de ordem psicológica (com variáveis latentes), permite usar múltiplos preditores e variáveis de critério, modelar erros de medição para variáveis observadas e testar relações de mediação e moderação em um único modelo (Fornell, 1985; Hair Jr. et al., 2016); (iii) a estimação simultânea de relações dependentes múltiplas e interrelacionadas entre variáveis e o uso de medidas de constructos latentes (Nitzl, 2016); (iv) está se tornando cada vez popular nos periódicos do mainstream da contabilidade gerencial (Nitzl, 2016); (v) é preferida em áreas de pesquisa com fundamentos teóricos abrangentes (Henseler, Ringle, \& Sinkovics, 2009), que é uma característica generalizada da atual pesquisa de sistemas de controle gerencial (Malmi \& Brown, 2008); (vi) não pressupõe distribuição normal dos dados (Henseler et al., 2009; Hair Jr. et al., 2016).

Para a avaliação dos resultados, foram realizadas análises em duas etapas como proposto por Hair Jr. et al. (2016). Inicialmente, foi analisado o modelo de mensuração, com o objetivo de assegurar a confiabilidade interna do modelo por meio dos seguintes procedimentos: (i) confiabilidade composta do modelo (composite reliability); (ii) confiabilidade individual dos itens (indicator reability); (iii) a validade convergente (average variance extracted - AVE), que mostra o quanto as medidas são convergentes para cada constructo; (iv) validade discriminante (discriminant validity) com indicação das diferenças representadas por cada constructo no modelo (Hair Jr. et al., 2016).

Em seguida, foi analisado o modelo estrutural com os seguintes procedimentos: (i) problemas de colinearidade dos constructos; (ii) coeficientes de caminho (path coeficients - $\beta$ ); (iii) níveis de significância ( $p$ value); (iv) coeficientes de determinação $\left(\mathrm{r}^{2}\right)$ para as variâncias explicadas dos constructos endógenos (Henseler et al., 2009).

\section{Resultados e discussões}

Para análise dos resultados, foi avaliado o modelo a partir dos eventos criados para cada tipo de controle individualmente. Dessa forma, verifica-se o efeito que o controle de resultado, de ação, de pessoal e cultural gerou individualmente no comprometimento afetivo. Inicialmente, foi analisada a confiabilidade do modelo teórico para os quatro tipos de controle, conforme indicado por Hair Jr. et al. (2016). 


\subsection{Confiabilidade interna}

Verificou-se que os cenários experimentais elaborados para os quatro tipos de controle apresentaram boa confiabilidade interna, com CR, AVE e VD satisfatórios, conforme demonstrado na Tabela 2. Para análise da validade discriminante, foi utilizado o critério de Fornell-Larcker, com resultados superiores a 0,8 , descartando assim problemas de multicolinearidade.

Tabela 2

\section{Confiabilidade interna do modelo teórico}

\begin{tabular}{|c|c|c|c|c|}
\hline CONTRUCTOS & Alpha & CR & AVE & VD \\
\hline Controle de Resultado & 0,82 & 0,87 & 0,57 & Sim \\
\hline Desafio & 0,79 & 0,88 & 0,70 & Sim \\
\hline Ameaça & 0,82 & 0,89 & 0,73 & Sim \\
\hline Afeto Positivo & 0,87 & 0,91 & 0,67 & Sim \\
\hline Afeto Negativo & 0,86 & 0,90 & 0,65 & Sim \\
\hline Comprometimento afetivo & 0,83 & 0,91 & 0,63 & Sim \\
\hline Controle de Ação & 0,81 & 0,87 & 0,57 & Sim \\
\hline Desafio & 0,77 & 0,87 & 0,69 & Sim \\
\hline Ameaça & 0,87 & 0,93 & 0,82 & Sim \\
\hline Afeto Positivo & 0,89 & 0,92 & 0,69 & Sim \\
\hline Afeto Negativo & 0,86 & 0,90 & 0,64 & Sim \\
\hline Comprometimento afetivo & 0,89 & 0,92 & 0,65 & Sim \\
\hline Controle de Pessoal & 0,87 & 0,90 & 0,65 & Sim \\
\hline Desafio & 0,81 & 0,88 & 0,72 & Sim \\
\hline Ameaça & 0,88 & 0,92 & 0,80 & Sim \\
\hline Afeto Positivo & 0,94 & 0,95 & 0,80 & Sim \\
\hline Afeto Negativo & 0,82 & 0,88 & 0,59 & Sim \\
\hline Comprometimento afetivo & 0,89 & 0,91 & 0,64 & Sim \\
\hline Controle Cultural & 0,83 & 0,88 & 0,61 & Sim \\
\hline Desafio & 0,79 & 0,87 & 0,70 & Sim \\
\hline Ameaça & 0,91 & 0,95 & 0,85 & Sim \\
\hline Afeto Positivo & 0,92 & 0,94 & 0,75 & Sim \\
\hline Afeto Negativo & 0,87 & 0,90 & 0,66 & Sim \\
\hline Comprometimento afetivo & 0,82 & 0,87 & 0,54 & Sim \\
\hline
\end{tabular}

Após a confirmação da confiabilidade do modelo de medidas, verificou-se então a significância das relações, por meio do procedimento Complete Bootstrapping. Foram utilizadas 5.000 interações sem mudança de sinal para um teste bicaudal, conforme indicado por Hair Jr. et al. (2016).

\subsection{Modelo estrutural}

Nesta etapa, apresentam-se os resultados de maneira a analisar de forma conjunta o CG, e permitir comparar os controles gerenciais em cada etapa do modelo de pesquisa. Complementarmente, é apresentado um modelo estrutural que contempla os efeitos dos quatro controles de forma conjunta (CG), uma vez que os participantes da pesquisa responderam às quatro simulações, conforme exibido na Figura 5. 


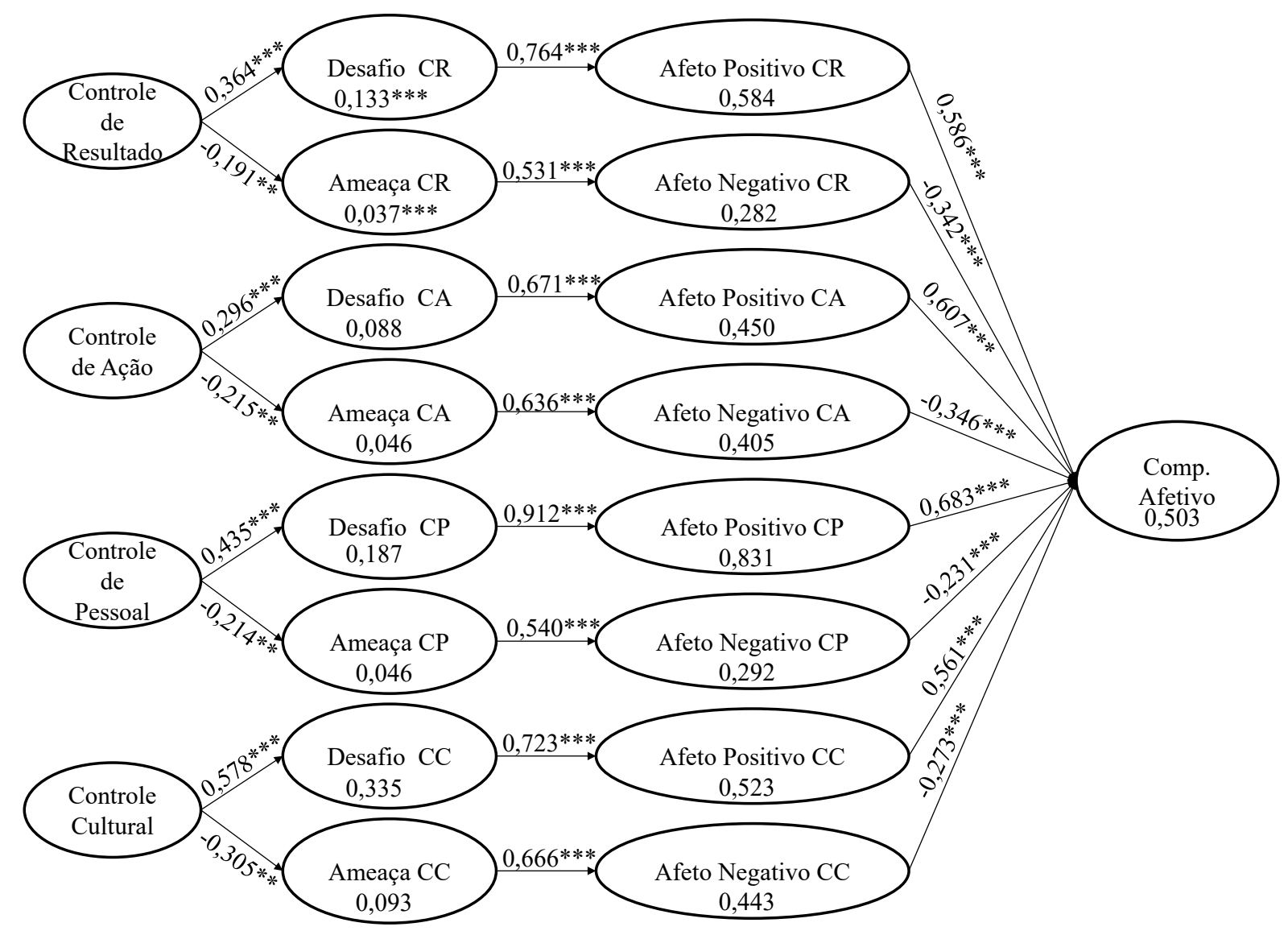

Figura 5. Modelo estrutural para o CG

Sobre as avaliações cognitivas positivas (desafio), os controles cultural e de pessoal foram percebidos com maior intensidade, quando comparados aos controles de resultado e de ação. Em contrapartida, o controle de ação resultou no menor efeito na avaliação cognitiva positiva, ou seja, indicaram menor motivação e estímulo. Os resultados estão em linha com a literatura de controles gerenciais (Hutzschenreuter, 2009; Goebel \& Weißenberger, 2017), a qual prevê efeitos mais positivos para os controles culturais e de pessoal, em relação aos controles de resultado e de ação. Portanto, entende-se que organizações podem alcançar resultados cognitivos positivos com maior intensidade ao adotar esses dois tipos de controles. As hipóteses secundárias para a avaliação cognitiva são exibidas na Tabela 3.

Tabela 3

Hipóteses para a avaliação cognitiva de controles gerenciais

\begin{tabular}{cccccc}
\hline Hipótese & Sentido & Relação & Resultado & Coef & r2 \\
\hline $\mathrm{H} 1 \mathrm{a}$ & $(+)$ & $\mathrm{CR} \rightarrow \mathrm{DES}$ & Aceita & $0.364^{* * *}$ & 0.133 \\
\hline $\mathrm{H} 1 \mathrm{~b}$ & $(+)$ & $\mathrm{CA} \rightarrow \mathrm{DES}$ & Aceita & $0.296^{* * *}$ & 0.088 \\
\hline $\mathrm{H} 1 \mathrm{C}$ & $(+)$ & $\mathrm{CP} \rightarrow \mathrm{DES}$ & Aceita & $0.435^{* * *}$ & 0.190 \\
\hline $\mathrm{H} 1 \mathrm{~d}$ & $(+)$ & $\mathrm{CC} \rightarrow \mathrm{DES}$ & Aceita & $0.578^{* * *}$ & 0.335 \\
\hline $\mathrm{H} 2 \mathrm{a}$ & $(-)$ & $\mathrm{CR} \rightarrow \mathrm{AME}$ & Aceita & $-0.191^{* *}$ & 0.037 \\
\hline $\mathrm{H} 2 \mathrm{~b}$ & $(-)$ & $\mathrm{CA} \rightarrow \mathrm{AME}$ & Aceita & $-0.215^{* *}$ & 0.046 \\
\hline $\mathrm{H} 2 \mathrm{c}$ & $(-)$ & $\mathrm{CP} \rightarrow \mathrm{AME}$ & Aceita & $-0.214^{* *}$ & 0.046 \\
\hline $\mathrm{H} 2 \mathrm{~d}$ & $(-)$ & $\mathrm{CC} \rightarrow \mathrm{AME}$ & Aceita & $-0.305^{* *}$ & 0.093 \\
\hline
\end{tabular}

*** Significância de $1 \%$

** Significância de 5\% 
As avaliações de ameaça, por outro lado, indicam uma relação negativa com a adoção de CG, ou seja, os controles gerenciais reduziram a sensação de ameaça em relação aos cenários de controle gerencial. Nesse sentido, destaca-se o controle cultural, que apresenta o efeito mais intenso nessa relação em comparação aos demais. Observa-se também que, embora todas as relações tenham se mostrado significativas, os cenários projetados foram recebidos mais fortemente de forma positiva do que negativa.

Em relação às reações emocionais, espera-se um aumento no afeto positivo entre os participantes que avaliaram os controles gerenciais de forma positiva (desafio). Os resultados para os quatro controles apresentados estão alinhados. De forma oposta, é esperado um aumento nos níveis de afeto negativo para os indivíduos que avaliam como ameaçadora a adoção dos controles gerenciais. Essa relação se destacou para os controles de pessoal e de ação, todavia, todos os controles gerenciais apresentaram níveis similares de intensidade.

Tabela 4

Hipóteses sobre as reações emocionais provocadas

\begin{tabular}{ccccccc}
\hline Hipótese & Controle & Sentido & Relação & Resultado & Coef & r2 \\
\hline $\mathrm{H} 3 \mathrm{a}$ & $\mathrm{CR}$ & $(+)$ & $\mathrm{DES} \rightarrow \mathrm{AP}$ & Aceita & $0.764^{* * *}$ & 0.583 \\
\hline $\mathrm{H} 3 \mathrm{~b}$ & $\mathrm{CA}$ & $(+)$ & $\mathrm{DES} \rightarrow \mathrm{AP}$ & Aceita & $0.670^{* * *}$ & 0.449 \\
\hline $\mathrm{H} 3 \mathrm{c}$ & $\mathrm{CP}$ & $(+)$ & $\mathrm{DES} \rightarrow \mathrm{AP}$ & Aceita & $0.762^{* * *}$ & 0.581 \\
\hline $\mathrm{H} 3 \mathrm{~d}$ & $\mathrm{CC}$ & $(+)$ & $\mathrm{DES} \rightarrow \mathrm{AP}$ & Aceita & $0.723^{* * *}$ & 0.522 \\
\hline $\mathrm{H} 4 \mathrm{C}$ & $\mathrm{CR}$ & $(+)$ & $\mathrm{AME} \rightarrow \mathrm{NA}$ & Aceita & $0.532^{* * *}$ & 0.283 \\
\hline $\mathrm{H} 4 \mathrm{~b}$ & $\mathrm{CA}$ & $(+)$ & $\mathrm{AME} \rightarrow \mathrm{NA}$ & Aceita & $0.640^{* * *}$ & 0.409 \\
\hline $\mathrm{H} 4 \mathrm{c}$ & $\mathrm{CP}$ & $(+)$ & $\mathrm{AME} \rightarrow \mathrm{NA}$ & Aceita & $0.545^{* * *}$ & 0.297 \\
\hline $\mathrm{H} 4 \mathrm{~d}$ & $\mathrm{CC}$ & $(+)$ & $\mathrm{AME} \rightarrow \mathrm{NA}$ & Aceita & $0.666^{* * *}$ & 0.444 \\
\hline
\end{tabular}

*** Significância de 1\% ** Significância de 5\%

De forma geral, percebe-se que o CG provoca impacto emocional nos indivíduos, o que demostra ser este um aspecto relevante para a investigação dos efeitos individuais dos controles gerenciais. Estes resultados corroboram com os achados de Trivellas, Reklitis e Platis (2013), que a avaliação cognitiva positiva está relacionada a afeto positivo, e de Fugate, Harrison e Kinicki (2011), que mostraram a relação entre a avaliação cognitiva de ameaça e afeto negativo na percepção sobre a adoção de CG. Os resultados podem ser observados na Tabela 4. 
Ao examinar os caminhos que provocam efeitos no comprometimento afetivo dos empregados, é esperado um aumento no comprometimento afetivo em indivíduos que sentiram afeto positivo. Essa relação mostrou-se mais intensa para o controle de pessoal e ratificou os resultados dos constructos antecedentes no modelo. Desta maneira, entende-se que indivíduos tiveram um impacto positivo mais intenso quando a organização propõe a integração dos empregados, oferece treinamentos que desenvolvem capacidades e promovem um clima interpessoal favorável. Esses achados corroboram em parte os resultados de Goebel e Weißenberger (2017), ao mostrarem que os controles de pessoal e culturais influenciam positivamente o comprometimento. Os demais controles apresentados também indicam um impacto positivo, porém, em níveis mais baixos, conforme Tabela 5.

Tabela 5

Hipóteses sobre os efeitos no comprometimento afetivo

\begin{tabular}{ccccccc}
\hline Hipótese & Controle & Sentido & Relação & Resultado & Coef & r2 \\
\hline H5a & CR & $(+)$ & AP $\rightarrow$ CAF & Aceita & $0.586^{* * *}$ & 0.502 \\
\hline H5b & CA & $(+)$ & AP $\rightarrow$ CAF & Aceita & $0.607^{* * *}$ & 0.490 \\
\hline H5c & CP & $(+)$ & AP $\rightarrow$ CAF & Aceita & $0.683^{* * *}$ & 0.560 \\
\hline H5d & CC & $(+)$ & AP $\rightarrow$ CAF & Aceita & $0.561^{* * *}$ & 0.380 \\
\hline H6a & CR & $(-)$ & AN $\rightarrow$ CAF & Aceita & $-0.342^{* * *}$ & 0.502 \\
\hline H6b & CA & $(-)$ & AN $\rightarrow$ CAF & Aceita & $-0.346^{* * *}$ & 0.490 \\
\hline H6c & CP & $(-)$ & AN $\rightarrow$ CAF & Aceita & $-0.231^{* * *}$ & 0.560 \\
\hline H6d & CC & $(-)$ & AN $\rightarrow$ CAF & Aceita & $-0.273^{* * *}$ & 0.380 \\
\hline$* * *$ Significância de 1\% & & $* *$ Significância de $5 \%$ & & &
\end{tabular}

Por fim, para os indivíduos que perceberam o controle como uma ameaça e sentiram afetos negativos, era esperado uma diminuição no comprometimento. Essa relação foi mais intensa para os controles de resultado e de ação. Isto é, quando percebidos negativamente pelo empregado, tais controles podem limitar o comprometimento afetivo. É importante destacar que os efeitos no comprometimento afetivo se mostraram sempre positivos quando o indivíduo percebe os controles de forma positiva. Em outro sentido, os que perceberam e sentiram os controles de maneira negativa revelaram diminuição no comprometimento afetivo, porém de forma mais moderada em relação ao caminho positivo.

Adicionalmente aos testes de hipóteses propostas para este estudo, foram gerados modelos estruturais da pesquisa utilizando as variáveis demográficas dos participantes para separação da amostra obtida. Isso para verificar possíveis influências e diferenças individuais que possam apontar caminhos alternativos para a interpretação e o refinamento dos resultados. De maneira geral, as análises segregadas por variáveis de controle (gênero, idade, estado civil e tempo de experiência profissional) também confirmaram as relações e sentidos esperados nas hipóteses de pesquisa, não indicando possíveis diferenças a partir de características demográficas dos participantes.

Este estudo amplia a compreensão da complexidade cognitiva, afetiva e comportamental (atitudes) envolvida na experiência do empregado com a adoção de CG. E fornece elementos para desvendar o papel das emoções no trabalho e os processos psicológicos subjacentes a elas. Os achados fornecem informações importantes para a teoria e a prática com relação ao desenho de CG nas organizações, por contribuir para o desenvolvimento de teorias de controle gerencial que consideram fatores psicológicos dos indivíduos envolvidos na adoção de CG. 
De maneira prática, os achados evidenciam como gestores podem implementar e gerenciar a adoção de CG, a partir de caminhos psicológicos distintos na aplicação de diferentes tipos de controles gerenciais. Isso permite identificar o modo como empregados avaliam cognitivamente e são afetados emocionalmente por eles, sendo importante para avaliar riscos e benefícios no desenho e uso de CG.

Os resultados deste estudo também sugerem benefícios às organizações para a adoção de controles avaliados e sentidos de maneira positiva. Portanto, é importante para os gestores enquadrar as mudanças positivamente e articular os benefícios da mudança para a organização e indivíduos afetados. O envolvimento dos empregados na adoção dos controles provavelmente fará com que se sintam mais informados e controlem o impacto das mudanças, o que reduzirá as avaliações negativas e possíveis resultados prejudiciais à organização.

\section{Conclusões}

O objetivo do estudo foi analisar os efeitos dos controles gerenciais no comprometimento afetivo por meio das avaliações cognitivas e reações emocionais. O estudo foi realizado por meio de quatro cenários realizadas com 252 estudantes de graduação da área de gestão.

Os resultados mostram que os controles (de resultado, ação, pessoal e cultural) geram impactos positivos sobre o processo emocional de subordinados, gerando comportamentos positivos às organizações. Além destes impactos não apresentarem a mesma intensidade, o que mostra que os controles gerenciais devem ser desenhados com foco nos fatores comportamentais dos indivíduos, que facilitam o alinhamento entre os objetivos individuais e organizacionais.

A análise conjunta da adoção de controles gerenciais fornece evidências de que os elementos são importantes para promover os comportamentos desejados dos empregados. As organizações podem se beneficiar direcionando o foco dos controles para controles indiretos (pessoal e cultural), que indicam resultados cognitivos, emocionais e atitudinais positivos, com maior intensidade. Assim, o CG deve ser considerado como importante aspecto organizacional que afeta os comportamentos dos empregados e o seu comprometimento com as tarefas desempenhadas. Nesse sentido, direciona as atitudes individuais que foram representadas nesta pesquisa pelo comprometimento afetivo na organização.

Mesmo com todo o cuidado em relação aos procedimentos de pesquisa, é preciso reconhecer algumas limitações importantes. A primeira delas diz respeito à avaliação cognitiva do indivíduo. Embora a amostra represente um conjunto de opiniões individuais, é preciso reconhecer que um grupo influencia a opinião individual como sugere a literatura de psicologia social, e esse efeito não pôde ser captado nesta pesquisa.

Outra questão importante é que a opção metodológica de se utilizar estudantes para modelagem de cenários empresariais, apesar de possibilitar melhor controle do ambiente experimental, reduz a confiabilidade externa do quase-experimento e, portanto, um maior risco para generalizações no ambiente real. Como destacam Shadish et al. (2002), as questões sobre validade externa envolvem saber se uma relação causal utilizada no estudo se mantém sobre as pessoas e ambientes reais.

A modelagem de equações está sujeita às limitações relacionadas à análise baseada na variância. Assim, foram realizados procedimentos para validação e confiabilidade dos itens e constructos analisados, por meio de pré-testes aplicados com voluntários e especialistas e teste-piloto com uma amostra por conveniência. Nesse sentido, os resultados desta pesquisa devem ser entendidos como um caminho importante a ser considerado em pesquisas futuras de campo e não como conclusões definitivas.

Recomenda-se a continuidade desta pesquisa em buscas empíricas dentro das organizações para comparação e expansão dos resultados. Os resultados e discussões provocadas por esta pesquisa indicam que cada tipo de controle pode provocar uma reação diferente em cada indivíduo. Portanto, a aceitação de que o CG influencia comportamento sem maiores conhecimentos sobre essa influência, pode ser uma explicação para os resultados inconsistentes encontrados nos estudos amparados na Teoria Contingencial. 
Acerca do desenvolvimento desta linha de pesquisa, este é um primeiro diagnóstico para se analisar as relações e a maneira na qual fatores emocionais e psicológicos podem ser considerados nos estudos sobre CG. Assim, parece consistente o fato de que os controles de gestão provocam uma variação nos componentes emocionais e de comprometimento afetivo, o que podem ser determinantes no desempenho do empregado e da própria organização. O papel dos controles gerenciais no comportamento dos indivíduos é fundamental para provocar congruência e realização de objetivos pessoais e organizacionais, e parece benéfico para as organizações desenvolver sentimentos positivos nos empregados (Goebel \& Weißenberger, 2017).

\section{Referências}

Aguiar, A. B. (2017). Pesquisa experimental em contabilidade: propósito, desenho e execução. Advances in Scientific and Applied Accounting, 10(2), 224-244. Doi: http://dx.doi.org/10.14392/asaa.2017100206

Ashkanasy, N. M., \& Humphrey, R. H. (2011). Current emotion research in organizational behavior. Emotion review, 3(2), 214-224. Doi: https://doi.org/10.1177/1754073910391684

Ashkanasy, N. M., \& Daus, C. S. (2002). Emotion in the workplace: The new challenge for managers. Academy of Management Perspectives, 16(1), 76-86. Doi: https://doi.org/10.5465/ame.2002.6640191

Ashkanasy, N. M., Härtel, C. E., \& Daus, C. S. (2002). Diversity and emotion: The new frontiers in organizational behavior research. Journal of management, 28(3), 307-338. Doi: https://doi. org/10.1177/014920630202800304

Basch, J., \& Fisher, C. D. (1998). Affective events-emotions matrix: A classification of work events and associated emotions (Discussion Paper n. 65). School of Business, Bond University, San Diego, CA.

Basnet, B. J. (2018). Total Quality Management Practices on Employees' Job Involvement in Nepalese Manufacturing Industry. Pravaha, 24(1), 18-30. Doi: https://doi.org/10.3126/pravaha.v24i1.20222

Biggane, J. E., Allen, D. G., \& Albert, L. S. (2016). The role of positive illusions in employment relationships. Human Resource Management Review, 26(3), 270-281. Doi: https://doi.org/10.1016/j. hrmr.2016.03.003

Birnberg, J. G., \& Ganguly, A. R. (2012). Is neuroaccounting waiting in the wings? An essay. Accounting, Organizations and Society, 37(1), 1-13. Doi: https://doi.org/10.1016/j.aos.2011.11.004

Brief, A. P., \& Weiss, H. M. (2002). Organizational behavior: Affect in the workplace. Annual review of psychology, 53(1), 279-307. Doi: https://doi.org/10.1146/annurev.psych.53.100901.135156

Charness, G., Gneezy, U., \& Kuhn, M. A. (2012). Experimental methods: Between-subject and withinsubject design. Journal of Economic Behavior \& Organization, 81(1), 1-8. Doi: https://doi. org/10.1016/j.jebo.2011.08.009

Chenhall, R. H., \& Moers, F. (2015). The role of innovation in the evolution of management accounting and its integration into management control. Accounting, organizations and society, 47, 1-13. Doi: https://doi.org/10.1016/j.aos.2015.10.002

Christ, M. H., Sedatole, K. L., Towry, K. L., \& Thomas, M. A. (2008). When formal controls undermine trust and cooperation. Strategic finance, 89(7), 39-45.

Christ, M. H., Emett, S. A., Summers, S. L., \& Wood, D. A. (2012). The effects of preventive and detective controls on employee performance and motivation. Contemporary Accounting Research, 29(2), 432452. Doi: https://doi.org/10.1111/j.1911-3846.2011.01106.x 
Christ, M. H., Emett, S. A., Tayler, W. B., \& Wood, D. A. (2016). Compensation or feedback: Motivating performance in multidimensional tasks. Accounting, Organizations and Society, 50, 27-40. Doi: https://doi.org/10.1016/j.aos.2016.03.003

Clore, G. L., \& Ortony, A. (2000). Cognition in emotion: Always, sometimes, or never. Cognitive neuroscience of emotion, 24-61. Recuperado em 31/08/21 em: https:/www.researchgate.net/ publication/308468924_Cognition_in_emotion_Always_sometimes_or_never

Cobb, A. T., Wooten, K. C., \& Folger, R. (1995). Justice in the making: Toward understanding the theory and practice of justice in organizational change and development. Research in organizational change and development, 8(1), 243-295. Recuperado em 31/08/21 em: https://www.researchgate. net/scientific-contributions/KC-Wooten-2126632302

Cugueró-Escofet, N., \& Rosanas, J. M. (2013). The just design and use of management control systems as requirements for goal congruence. Management accounting research, 24(1), 23-40. Doi: https://doi. org/10.1016/j.mar.2012.11.001

Dutton, J. E., Ashford, S. J., O’neill, R. M., Hayes, E., \& Wierba, E. E. (1997). Reading the wind: How middle managers assess the context for selling issues to top managers. Strategic management journal, 18(5), 407-423. Doi: https://doi.org/10.1002/(SICI)1097-0266(199705)18:5<407::AID-SMJ881>3.0.CO;2-J

Fávero, L. P.; Silva, F. L.; Belfiore, P.; Chan, B. (2009). Análise de dados: modelagem multivariada para tomada de decisões. Rio de Janeiro, RJ: Elselvier.

Field, A. (2009). Descobrindo a estatística usando o SPSS-5. Porto Algre, RS: Penso Editora.

Fisher, V. E., \& Hanna, J. V. (1931). The dissatisfied worker. MacMillan Co. Doi: https://doi. org/10.1037/10719-000

Fornell, C. (1985, Janeiro). A second generation of multivariate analysis: Classification of methods and implications for marketing research. (Working paper n. 414). The University of Michigan. Ann Arbor, Michigan.

Fredrickson, B. L. (1998). What good are positive emotions?. Review of general psychology, 2(3), 300-319. Doi: https://doi.org/10.1037/1089-2680.2.3.300

Frijda, N. H. (1986). The emotions. Cambridge, UK: Cambridge University Press.

Fridja, N. H. (1993). Moods, emotion episodes, and emotions, (381-404). Handbook of emotions. New York, USA: The Guilford Press.

Frijda, N. H. (2004, Abril). Emotions and Action. In A. S. R. Manstead, N. Frijda, \& A. Fischer (Eds.), Studies in emotion and social interaction. Feelings and emotions: The Amsterdam symposium (p. 158-173). Cambridge, UK: Cambridge University Press. Doi: https://doi.org/10.1017/ CBO9780511806582.010

Fugate, M., Harrison, S., \& Kinicki, A. J. (2011). Thoughts and feelings about organizational change: A field test of appraisal theory. Journal of Leadership \& Organizational Studies, 18(4), 421-437. Doi: https://doi.org/10.1177/1548051811416510

Galinha, I. C., Pereira, C. R., \& Esteves, F. (2014). Versão reduzida da escala portuguesa de afeto positivo e negativo-PANAS-VRP: Análise fatorial confirmatória e invariância temporal. Psicologia, 28(1), 50-62. Doi: https://doi.org/10.17575/rpsicol.v28i1.622

George, J. M. (1989). Mood and absence. Journal of applied psychology, 74(2), 317-324. Doi: https://doi. org/10.1037/0021-9010.74.2.317

George, J. M., \& Brief, A. P. (1992). Feeling good-doing good: a conceptual analysis of the mood at work-organizational spontaneity relationship. Psychological bulletin, 112(2), 310. Doi: https://doi. org/10.1037/0033-2909.112.2.310 
Goebel, S., \& Weißenberger, B. E. (2017). Effects of management control mechanisms: Towards a more comprehensive analysis. Journal of Business Economics, 87(2), 185-219. Doi: https://doi.org/10.1007/ s11573-016-0816-6.

Gomes, A. R., Faria, S., \& Gonçalves, A. M. (2013). Cognitive appraisal as a mediator in the relationship between stress and burnout. Work \& Stress, 27(4), 351-367. Doi: https://doi.org/10.1080/0267837 3.2013.840341

Hair Jr, J. F., Hult, G. T. M., Ringle, C., \& Sarstedt, M. (2016). A primer on partial least squares structural equation modeling (PLS-SEM). California, USA: Sage publications.

Henseler, J., Ringle, C. M., \& Sinkovics, R. R. (2009). The use of partial least squares path modeling in international marketing. In New challenges to international marketing. Bingley (Vol. 20, pp. 277-319). Bingley, UK: Emerald Group Publishing Limited. Doi: https://doi.org/10.1108/S14747979(2009)0000020014

Herath, S. K. (2007). A framework for management control research. Journal of management development, 26(9), 895-915. Doi: https://doi.org/10.1108/02621710710819366

Hernandez, M. (2008). Promoting stewardship behavior in organizations: A leadership model. Journal of business ethics, 80(1), 121-128. Doi: https://doi.org/10.1007/s10551-007-9440-2

Herscovitch, L., \& Meyer, J. P. (2002). Commitment to organizational change: Extension of a threecomponent model. Journal of applied psychology, 87(3), 474. Doi: https://doi.org/10.1037/00219010.87.3.474

Hersey, R. B. (1932). Workers' emotions in shop and home: a study of individual workers from the psychological and physiological standpoint, 165(1). Philadelphia: University of Pennsylvania Press. Doi: https://doi.org/10.1177/000271623316500141

Hoppock, R. (1935). Job satisfaction. Oxford: UK: Harper.

Hopwood, A. G. (1972). An empirical study of the role of accounting data in performance evaluation. Journal of accounting research, 10, 156-182. Doi: https://doi.org/10.2307/2489870

Hutzschenreuter, J. (2009). Management control in small and medium-sized enterprises: Indirect Control Forms, Control Combinations and their Effect on Company Performance. Wiesbaden, Alemanha: GWV Fachverlage. Doi: https://doi.org/10.1007/978-3-8349-8395-4

Huy, Q. N. (2002). Emotional balancing of organizational continuity and radical change: The contribution of middle managers. Administrative science quarterly, 47(1), 31-69. Doi: https://doi. org/10.2307/3094890

Ilies, R., Scott, B. A., \& Judge, T. A. (2006). The interactive effects of personal traits and experienced states on intraindividual patterns of citizenship behavior. Academy of Management Journal, 49(3), 561575. Doi: https://doi.org/10.5465/amj.2006.21794672

Karia, N., \& Asaari, M. H. A. H. (2006). The effects of total quality management practices on employees' work-related attitudes. The TQM magazine. Doi: https://doi.org/10.1108/09544780610637677

Kenis, I. (1979). Effects of budgetary goal characteristics on managerial atitudes and performance. The Accounting Review, 54(4), 707-721.

Kim, Y. M. (2009). Validation of psychometric research instruments: The case of information science. Journal of the American Society for Information Science and Technology, 60(6), 1178-1191. Doi: https://doi.org/10.1002/asi.21066

Kleine, C., \& Weißenberger, B. E. (2014). Leadership impact on organizational commitment: The mediating role of management control systems choice. Journal of Management Control, 24(3), 241-266. Doi: https://doi.org/10.1007/s00187-013-0181-3 
Kornhauser, A. W., \& Sharp, A. A. (1932). Employee attitudes; suggestions from a study in a factory. Personnel journal, 10, 393-404. Doi: https://doi.org/10.1111/j.1468-232X.1988.tb01047.x

Lazarus, R. S., \& Lazarus, R. S. (1991a). Emotion and adaptation. New York, NY: Oxford University Press.

Lazarus, R. S. (1991b). Progress on a cognitive-motivational-relational theory of emotion. American psychologist, 46(8), 819. Doi: https://doi.org/10.1037/0003-066X.46.8.819

Liu, Y., \& Perrewe, P. L. (2005). Another look at the role of emotion in the organizational change: A process model. Human Resource Management Review, 15(4), 263-280. Doi: https://doi.org/10.1016/j. hrmr.2005.12.001

Long, C. P. (2018). To control and build trust: How managers use organizational controls and trustbuilding activities to motivate subordinate cooperation. Accounting, Organizations and Society, 70, 69-91. Doi: https://doi.org/10.1016/j.aos.2018.05.006

Malmi, T., \& Brown, D. A. (2008). Management control systems as a package-Opportunities, challenges and research directions. Management accounting research, 19(4), 287-300. Doi: https://doi. org/10.1016/j.mar.2008.09.003

Matela, J. F. A. (2016). A influência da ética nas organizações: a mediação do clima ético nas relações de liderança com os resultados atitudinais dos colaboradores. (Dissertação de Mestrado). Instituto Universitário de Lisboa, Lisboa, Portugal.

Merchant, K. A., \& Van Der Stede, W. A. (2007). Management control systems: performance measurement, evaluation and incentives. Harlow, UK: Prentice Hall.

Meyer, J. P., \& Allen, N. J. (1997). Commitment in the workplace: Theory, research, and application. SAGE. Doi: http://dx.doi.org/10.4135/9781452231556

Neubert, M. J., Carlson, D. S., Kacmar, K. M., Roberts, J. A., \& Chonko, L. B. (2009). The virtuous influence of ethical leadership behavior: Evidence from the field. Journal of Business Ethics, 90(2), 157-170. Doi: https://doi.org/10.1007/s10551-009-0037-9

Nitzl, C. (2016). The use of partial least squares structural equation modelling (PLS-SEM) in management accounting research: Directions for future theory development. Journal of Accounting Literature, 37, 19-35. Doi: https://doi.org/10.1016/j.acclit.2016.09.003

Otley, D. (1999). Performance management: a framework for management control systems research. Management accounting research, 10(4), 363-382. Doi: https://doi.org/10.1006/ mare.1999.0115

Ortony, A., Clore, G. L., \& Collins, A. (1990). The cognitive structure of emotions. Cambridge, UK: Cambridge University Press. Doi: https://doi.org/10.1017/CBO9780511571299

Ouchi, W. G. (1979). A conceptual framework for the design of organizational control mechanisms. Management science, 25(9), 833-848. Doi: https://doi.org/10.1287/mnsc.25.9.833

Plutchik, R. (1994). The Psychology and Biology of Emotion. New York, NY: Harpercollins College Publishers.

Roethlisberger, F. J., \& Dickson. W. J. (1939). Management and the worker. Cambridge, MA: Harvard University Press.

Roseman, I. J., Spindel, M. S., \& Jose, P. E. (1990). Appraisals of emotion-eliciting events: Testing a theory of discrete emotions. Journal of personality and social psychology, 59(5), 899-915. Doi: https://doi. org/10.1037/0022-3514.59.5.899

Roseman, I. J., Wiest, C., \& Swartz, T. S. (1994). Phenomenology, behaviors, and goals differentiate discrete emotions. Journal of personality and social psychology, 67(2), 206-221. Doi: https://doi. org/10.1037/0022-3514.67.2.206 
Russell, J. A., \& Carroll, J. M. (1999). On the bipolarity of positive and negative affect. Psychological bulletin, 125(1), 3-30. Doi: https://doi.org/10.1037/0033-2909.125.1.3

Shadish, W. R., Cook, T. D., \& Campbell, D. T. (2002). Experimental and quasi-experimental designs for generalized causal inference. Boston: Houghton Mifflin.

Spence, J. R., Ferris, D. L., Brown, D. J., \& Heller, D. (2011). Understanding daily citizenship behaviors: A social comparison perspective. Journal of Organizational Behavior, 32(4), 547-571. Doi: https:// doi.org/10.1002/job.738

Sutton, R. I., \& Kahn, R. L. (1987). Prediction, understanding, and control as antidotes to organizational stress. Handbook of Organizational Behavior, 272-285. New Jersey, NY: Prentice Hall.

Trivellas, P., Reklitis, P., \& Platis, C. (2013). The effect of job related stress on employees' satisfaction: A survey in health care. Procedia-social and behavioral sciences, 73, 718-726. Doi: https://doi. org/10.1016/j.sbspro.2013.02.110

Van Maanen, J. E., \& Schein, E. H. (1977). Toward a theory of organizational socialization. (Working paper). MIT Sloan School of Management. Cambridge, MA.

Walton, R. E. (1985). From Control to Commitment in the Workplace: In factory after factory, there is a revolution under way in the management of work. (Working paper). US Department of Labor, Bureau of Labor-Management Relations and Cooperative Programs ,University of Illinois, Illinois, Chicago.

Watson, D., Clark, L. A., \& Tellegen, A. (1984). Cross-cultural convergence in the structure of mood: A Japanese replication and a comparison with US findings. Journal of Personality and Social Psychology, 47(1), 127-144. Doi: https://doi.org/10.1037/0022-3514.47.1.127

Weiss, H. M., \& Cropanzano, R. (1996). Affective events theory: A theoretical discussion of the structure, causes and consequences of affective experiences at work. In B. M. Staw \& L. L. Cummings (Eds.). Research in organizational behavior: An annual series of analytical essays and critical reviews. 18, 1-74. Amsterdan, NL: Elsevier Science/JAI Press. 